This article was downloaded by: [James Cook University]

On: 3 June 2009

Access details: Access Details: [subscription number 906377871]

Publisher Informa Healthcare

Informa Ltd Registered in England and Wales Registered Number: 1072954 Registered office: Mortimer House, 37-41 Mortimer Street, London W1T 3JH, UK

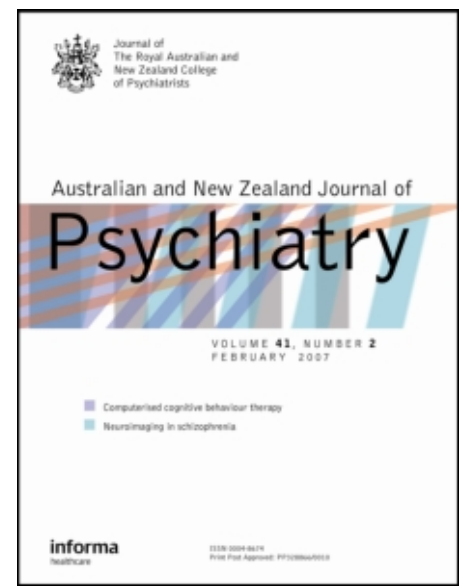

Australian and New Zealand Journal of Psychiatry

Publication details, including instructions for authors and subscription information: http://www.informaworld.com/smpp/title content=t768481832

\title{
Indigenous Australians' understandings regarding mental health and disorders
}

Valmae A. Ypinazar a; Stephen A. Margolis ${ }^{\text {b; }}$ Melissa Haswell-Elkins ${ }^{\text {a; }}$ Komla Tsey ${ }^{c}$

${ }^{a}$ North Queensland Health Equalities Promotion Unit, University of Queensland, School of Medicine, Cairns, Queensland, Australia ${ }^{b}$ School of Medicine, James Cook University, Cairns, Queensland, Australia ${ }^{\circ}$ School of Australian Indigenous Studies, James Cook University, Cairns, Queensland, Australia

Online Publication Date: 01 June 2007

To cite this Article Ypinazar, Valmae A., Margolis, Stephen A., Haswell-Elkins, Melissa and Tsey, Komla(2007)'Indigenous Australians' understandings regarding mental health and disorders',Australian and New Zealand Journal of Psychiatry,41:6,467 — 478

To link to this Article: DOI: $10.1080 / 00048670701332953$

URL: http://dx.doi.org/10.1080/00048670701332953

\section{PLEASE SCROLL DOWN FOR ARTICLE}

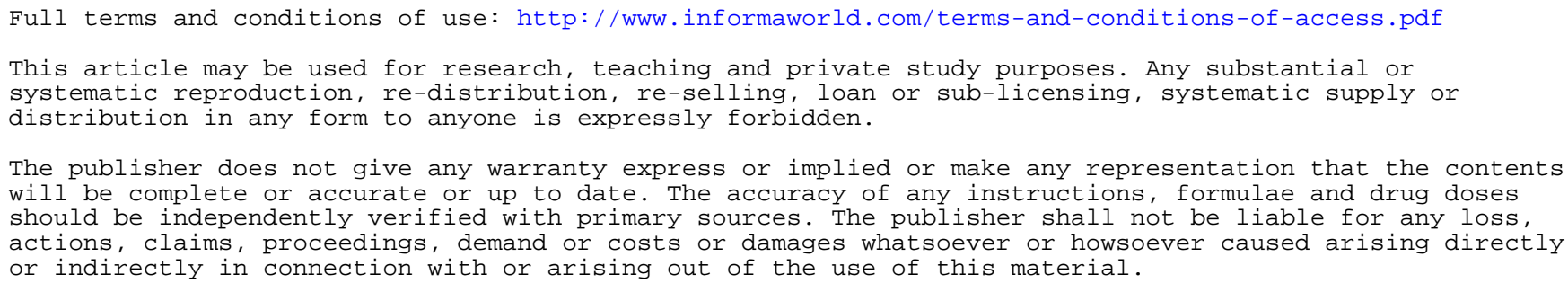

The publisher does not give any warranty express or implied or make any representation that the contents will be complete or accurate or up to date. The accuracy of any instructions, formulae and drug doses should be independently verified with primary sources. The publisher shall not be liable for any loss, actions, claims, proceedings, demand or costs or damages whatsoever or howsoever caused arising directly or indirectly in connection with or arising out of the use of this material. 


\title{
Indigenous Australians' understandings regarding mental health and disorders
}

\author{
Valmae A. Ypinazar, Stephen A. Margolis, Melissa Haswell-Elkins, \\ Komla Tsey
}

The purpose of the present paper was to determine what is currently documented about Indigenous Australians' understandings of mental health and mental disorders through a meta-synthesis of peer-reviewed qualitative empirical research. The following databases were electronically searched (1995-April 2006): AOA-FT and AIATSIS, Blackwell Synergy, CINAHL and Pre CINHAL, Health source: nursing/academic edition, Medline, Proquest health and medical complete, Psyclnfo, Science Direct, Synergy and HealthInfoNet. Eligible studies were those written in English and published in peerreviewed journals, empirical studies that considered Indigenous people's understandings of mental health and provided details on methodology. Five articles from four qualitative studies met these criteria. Meta-ethnography was used to identify common themes emerging from the original studies. Reciprocal translation was used to synthesize the findings to provide new interpretations extending beyond those presented in the original studies. An overarching theme emerged from the synthesis: the dynamic interconnectedness between the multi-factorial components of life circumstances. Reciprocal translations and synthesis regarding Indigenous understandings of mental health and illness resulted in five themes: (i) culture and spirituality; (ii) family and community kinships; (iii) historical, social and economic factors; (iv) fear and education; and (v) loss. The application of a meta-synthesis to these qualitative studies provided a deeper insight into Indigenous people's understandings of mental health and illness. The importance of understanding Indigenous descriptions and perceptions of mental health issues is crucial to enable two-way understandings between Indigenous people's constructs of wellness and Western biomedical diagnostic labels and treatment pathways for mental disorders and mental health problems.

Key words: Indigenous, mental health, meta-synthesis, qualitative, understandings.

\section{Australian and New Zealand Journal of Psychiatry 2007; 41:467-478}

Valmae A. Ypinazar, Research Fellow (Correspondence); Melissa Haswell-Elkins, Senior Lecturer

North Queensland Health Equalities Promotion Unit, University of Queensland, School of Medicine, 19 Aplin Street, PO Box 1103, Cairns, Queensland 4870, Australia. Email: v.ypinazar@uq.edu.au

Stephen A. Margolis, Associate Professor

School of Medicine, James Cook University, Cairns, Queensland, Australia

Komla Tsey, Associate Professor

School of Australian Indigenous Studies, James Cook University, Cairns, Queensland, Australia

Received 10 October 2006; accepted 21 February 2007.
Mental health concerns of Indigenous Australians constitute a major health problem in Australian society, yet there is a paucity of empirical research that specifically addresses the mental health needs of Indigenous people [1]. A recent content analysis conducted to determine the research status on mental health within the general Australian population for the year 1998 found that children and adolescents were the most researched subjects [2], while mental health issues of Indigenous people accounted for only $1.1 \%$ of the total articles. Indigenous people are not 
well researched or represented in the mental health literature [3].

The National Mental Health Strategy defines mental health as being more than the absence of illness; rather it describes a state of emotional and social well-being whereby the individual is able to function in their environment and with other people in a manner that enhances their innate capacity and cognitive, affective and relational mental abilities [4]. Mental health problems and mental health disorders 'refer to the spectrum of cognitive, emotional and behavioural disorders that interfere with the lives and productivity of people' [4]. A mental disorder is a diagnosable illness while a mental health problem is less severe but also interferes with a person's life; however, the distinction between the two is unclear [4]. For the purpose of this article the term 'mental disorder' is typically used but is intended to include mental health problems.

The lack of empirical research manifests itself in the subsequent quality and quantity of epidemiological and ethnographic data on mental disorders within the Aboriginal population [1,5,6]. In 1994 the Burdekin report argued: 'Despite the absence of epidemiological data, evidence presented to the Inquiry by Aboriginal people indicates that mental illness among Aboriginal and Torres Strait Islander people is a common and crippling problem. However, often, mental illness goes undiagnosed, unnoticed and untreated' [7].

At present the main measures of Indigenous mental disorders are derived from hospitalizations data and mortality due to serious mental disorders [8,9]. Data from such registers and service collections, however, are not an accurate indicator of the mental health status of Indigenous people due to difficulties of 'identification, categorization, attribution and interpretation' [6]. One of the difficulties encountered in the Burdekin and other reports is the inability to quantify the magnitude of mental health problems in the Indigenous population due to the absence of statistical data. Notwithstanding the lack of reliable data and population estimates, Indigenous people are widely thought to be at risk for increased deaths from suicide, demonstrate higher use of mental health services, and have higher hospital separations for mental disorders including a concomitant incidence of alcohol and drug diagnoses [10,11]. Without accurate data this lack of knowledge precludes the development and implementation of effective services and reduces the ability to target key service goals to meet individual and population-based needs.
The 1995 Ways Forward report contributed to the development of a national policy context for the emotional and social well-being of Indigenous Australians [12], becoming a landmark document in Indigenous mental health [13]. It described Indigenous views of health and mental health as "holistic, involving spiritual, social, emotional, cultural, physical and mental well-being and issues related to land and way of life' [12]. Additionally it provided the first comprehensive study that identified priorities for progressing Indigenous emotional and social well-being [10].

In 1993 and 1994 Aboriginal and Torres Strait Islander people were recognized as a priority group in the Queensland Mental Health Policy (1993) and Plan (1994) [14]. The aim of the Policy was to promote, improve and maintain the mental health and wellbeing of Indigenous people. The Policy acknowledged a holistic approach to health, stating that Indigenous people considered mental health to be a broad concept constituting social, emotional, cultural, physical and mental well-being, both of the individual and community, and is based on current, historical and spiritual values [14]. Despite numerous reports and policy documents that have identified health as a holistic construct and emphasized the importance of social and emotional well-being on mental health status, there appears to have been little improvement in the mental health and well-being of Indigenous people over the intervening years.

A concern often expressed by Indigenous people is that Western treatment models for mental health delivery do not take into account the Indigenous people's worldview or their cultural beliefs concerning mental health [15]. Cross-cultural psychiatry has influenced the delivery of mental health services to people of minority cultural groups for the past 30 years and emphasizes the importance of understanding the social, economic, historical and cultural factors that play a role in mental health problems and impact on treatment $[16,17]$. It is well established in the cross-cultural psychiatry literature that differing worldviews of cultural groups impact on their constructs of mental health, illness and physical wellbeing $[16,18]$. While many reports are developed through wide consultation and collaboration with Indigenous peoples, the actual voices of those on the ground are typically missing. Of import is the awareness that culture is a moving, living entity and changes over time [19]. Hence it is necessary to continue to explore and listen to the voices of Indigenous people to further understand both their cultural beliefs and their lived experience concerning mental health and mental health problems $[19,20]$. 
This article seeks to determine what is currently documented in the peer-reviewed literature regarding Indigenous Australians' worldview of mental health and disorders from their personal perspective through a meta-synthesis of qualitative empirical research.

\section{Methods}

Evidence-based-medicine has gained increased acceptance in informing medical care, and meta-analysis and systematic reviews are widely used to answer questions about various health-care issues [21]. Evidence-based-medicine and the synthesis of quantitative research findings have led, in part, to an interest in synthesizing the findings of qualitative research [22]. In order that the findings of qualitative research have impact there is a need for individual studies to be situated in a broader interpretive context through the meta-synthesis of qualitative research [23]. This is a relatively new approach but one that is gaining international acceptance as evidenced by recent publications [22,24,25].

Much of the work in qualitative meta-synthesis is informed by Noblit and Hare, who provided a framework for synthesizing qualitative studies through a process termed 'meta-ethnography' [26], an interpretive approach that seeks to identify concepts that are then considered across multiple studies included in the synthesis [24]. Meta-synthesis moves beyond the description and summarizing that typically occurs in a narrative literature review and aims to bring together qualitative research findings around a particular topic to 'achieve greater understanding and attain a level of conceptual or theoretical development beyond that achieved in any individual study' [22]. A meta-synthesis involves the translation of studies into one another with the purpose of understanding and transferring ideas and concepts across the individual studies [27]. Studies may relate to each other in three ways: reciprocal translations are those studies that may be directly comparable; refutational synthesis occurs when findings from studies may conflict with one another; and third, if taken together the synthesis may represent a line of argument [22,27]. Multiple examples of meta-synthesis occur in the literature with variations on the description and methods of reporting the analysis process.

With the dearth of information available concerning Indigenous people's perspectives of mental health and mental disorders it was deemed to be appropriate to synthesize the findings of individual studies to enhance the current knowledge base. The use of meta-synthesis is an important methodological contribution not previously used within Indigenous mental health.

\section{Search strategy}

Multiple databases were selected to ensure maximum retrieval of qualitative studies: AOA-FT and AIATSIS, Blackwell Synergy, CINAHL and Pre-CINHAL, Health source: nursing/academic edition, Medline, Proquest health and medical complete, PsycInfo, Science Direct, Synergy and HealthInfoNet. Keywords used were Indigenous, Aboriginal, Torres Strait Islander, mental health, mental illness, health, perceptions, understandings, beliefs, research and
Australia, and were used in multiple combinations. Inclusion criteria were empirical studies in English that considered Australian Indigenous people's understandings about mental health, described the methodology used and were published in peer-reviewed journals. Exclusion criteria included all articles and reports that were not based on empirical research, expert commentaries, opinion pieces and reports based on community consultation. The year 1995 was chosen as the beginning point due to the importance of the Ways Forward report in influencing subsequent approaches to mental health research [12].

As each database was searched, titles were checked and if indeterminable from title, abstracts (where available) were examined for relevance. A small number of articles could not be accessed due to institutional unavailability, removal from stated URLs, or inability to access government and other reports. References of selected articles were checked to ensure maximum coverage and allowed for the identification of studies not found using the key words. The construct of social and emotional wellbeing is often used when discussing mental health but the keyword 'health' typically recovered articles that had a mental health focus, including social and emotional well-being. Selected articles were printed in full for review. The search engine Google was used and captured multiple reports not published in peer reviewed journals.

The initial search located numerous articles and reports, but the majority of these were excluded following either a reading of the abstract or a review of the full text. Article exclusions were due to not meeting the inclusion criteria; in particular, the articles were not empirical qualitative research. For example one promising article was titled 'Exploration of Australian and New Zealand indigenous people's spirituality and mental health' [28]. The abstract stated that the authors were going to explore the concept of spirituality and use mental health in a practice setting. However, the article did not use qualitative methodology, was not empirical research and did not include Indigenous people's perspectives on the concept of spirituality and well-being, and hence was excluded. No articles that met the inclusion criteria were excluded upon subsequent review.

While a meta-analysis has a robust methodology with clearly defined processes and steps [29], the qualitative meta-synthesis does not have a similar defined pathway. Some authors argue the value of being inclusive in decision-making surrounding which studies to include in a meta-synthesis [24]. Appraisement of the quality of qualitative articles for inclusion in a meta-synthesis is a contentious issue [22]. Checklists to determine the quality of qualitative studies have been used by some researchers [22,30,31] while other researchers do not include a quality appraisement of qualitative studies in their meta-synthesis [24,25]. We aimed for inclusivity rather than subjecting the studies to rigorous quality analysis, as would occur in a meta-analysis. We determined the suitability of the identified studies based on whether qualitative methods were used for data collection and analysis and the findings were reported in a descriptive qualitative style.

\section{Analysis}

This meta-synthesis used the principles of reciprocal translation to synthesize the identified studies. Key themes determined by the 
original authors were listed and considered for the purpose of identifying commonalities of themes across the studies (Table 1). Articles were read multiple times with key concepts from each study being identified and mapped across the studies, the aim being to translate the findings from one study into another [22,24,27]. Concepts that were identified through this process became the data for the synthesis. For example, key concepts from one article may be similar to another study, but may also be different in some way;

Table 1. Investigated studies

\begin{tabular}{|c|c|c|c|c|c|}
\hline Authors/year & Location & Participants & Study year/s & Methodology & $\begin{array}{l}\text { Second order } \\
\text { constructs: Key themes by } \\
\text { authors from original data }\end{array}$ \\
\hline $\begin{array}{l}\text { Vicary and } \\
\text { Bishop } \\
2004[15]\end{array}$ & $\begin{array}{l}\text { Western } \\
\text { Australia: Perth } \\
\text { \& Kimberley } \\
\text { regions }\end{array}$ & $\begin{array}{l}70 \\
\text { Indigenous } \\
\text { people }\end{array}$ & $2000-2002$ & $\begin{array}{l}\text { Participatory action } \\
\text { research } \\
\text { In-depth interviews } \\
\text { Focus group } \\
\text { interviews }\end{array}$ & $\begin{array}{l}\text { Importance of culture } \\
\text { Conceptualizations of mental } \\
\text { health } \\
\text { Importance of Aboriginal } \\
\text { mental health treatment } \\
\text { methodologies } \\
\text { Appropriateness of Western } \\
\text { psychotherapy }\end{array}$ \\
\hline $\begin{array}{l}\text { Vicary and } \\
\text { Westerman } \\
2005 \text { [32] }\end{array}$ & $\begin{array}{l}\text { Western } \\
\text { Australia: } \\
\text { Perth and } \\
\text { Kimberley } \\
\text { regions }\end{array}$ & $\begin{array}{l}70 \\
\text { Indigenous } \\
\text { people }\end{array}$ & $2000-2002$ & $\begin{array}{l}\text { Participatory action } \\
\text { research } \\
\text { In-depth interviews } \\
\text { Focus group } \\
\text { interviews }\end{array}$ & $\begin{array}{l}\text { Depression } \\
\text { Culture } \\
\text { Spirituality } \\
\text { Concept of wellness } \\
\text { Indigenous treatment } \\
\text { Concern about contact with } \\
\quad \text { Western mental health } \\
\text { service }\end{array}$ \\
\hline $\begin{array}{l}\text { Emden et al. } \\
2005 \text { [11] } \\
\text { [This study } \\
\text { mainly had } \\
\text { to do with } \\
\text { medication } \\
\text { compli- } \\
\text { ance; not } \\
\text { all themes } \\
\text { relevant] }\end{array}$ & $\begin{array}{l}\text { South Australia: } \\
\text { Urban, } \\
\text { rural and } \\
\text { remote areas }\end{array}$ & $\begin{array}{l}130 \text { carers, } \\
\text { patients, } \\
\text { and mental } \\
\text { health } \\
\text { workers. } \\
\text { Most } \\
\text { participants } \\
\text { Indigenous }\end{array}$ & $\begin{array}{l}\text { July } 2000- \\
\text { June } 2003\end{array}$ & $\begin{array}{l}\text { Action research } \\
\quad \text { framework } \\
\text { In-depth interviews } \\
\text { Focus groups }\end{array}$ & $\begin{array}{l}\text { Social and emotional } \\
\text { well-being issues pervasive } \\
\text { Aboriginal service providers } \\
\text { subject to same stressors } \\
\text { as rest of community } \\
\text { Mainstream health services } \\
\text { do not meet lifestyles and } \\
\text { health problems of people } \\
\text { Trust and confidentiality } \\
\text { concerns in accessing } \\
\text { Aboriginal health services } \\
\text { Lack of English-language } \\
\text { literacy skills [medication] } \\
\text { Inadequate living } \\
\text { arrangements [medication] } \\
\text { Alcohol misuse [medication] } \\
\text { Racism impact on feelings of } \\
\text { self-respect and self-worth }\end{array}$ \\
\hline $\begin{array}{l}\text { McLennan } \\
\text { and } \\
\text { Khavarpour } \\
2004[34]\end{array}$ & $\begin{array}{l}\text { New South } \\
\text { Wales } \\
\text { Aboriginal } \\
\text { community }\end{array}$ & $\begin{array}{l}6 \text { Indigenous } \\
\text { people }\end{array}$ & 2003 & $\begin{array}{l}\text { Exploratory study } \\
\text { using qualitative } \\
\text { methodology } \\
\text { Semi-structured } \\
\text { interviews }\end{array}$ & $\begin{array}{l}\text { Identity } \\
\text { Family and community kinship } \\
\text { Culture and spirituality } \\
\text { Land }\end{array}$ \\
\hline $\begin{array}{l}\text { O'Brien } 2005 \\
\text { [33] }\end{array}$ & $\begin{array}{l}\text { New South } \\
\text { Wales } \\
\text { Aboriginal } \\
\text { community }\end{array}$ & $\begin{array}{l}27 \\
\text { Indigenous } \\
\text { people }\end{array}$ & $\begin{array}{l}\text { No year } \\
\text { provided }\end{array}$ & $\begin{array}{l}\text { Qualitative } \\
\text { methodology } \\
\text { In-depth interviews }\end{array}$ & $\begin{array}{l}\text { Defining Aboriginal mental } \\
\text { health and mental illness } \\
\text { Kinship and mental health } \\
\text { Alcohol and its relationship to } \\
\text { kinship and mental health } \\
\text { Living with shame } \\
\text { Expression of mental anguish } \\
\text { Role models, elders and } \\
\text { mental health } \\
\text { Loss of cultural identity (and } \\
\text { mental health) } \\
\text { Crisis of spirituality }\end{array}$ \\
\hline
\end{tabular}


these findings were then considered with the third study and so on until all studies had been considered [31]. These were considered in relation to the original themes because the aim was to maintain the integrity of the individual studies. Following the reciprocal translation phase a synthesis of the translations was conducted to elucidate core themes across the studies [29]. A grid was developed in which the themes across studies were listed and the concepts identified in each study juxtaposed, ensuring that each concept from each study was included (Table 2).

\section{Results}

Five articles from four studies were identified (Table 1). The articles were published in a range of journals: psychology, mental health, health promotion and primary health, reflecting the diversity of the field of study. These studies were carried out in Western Australia, South Australia and New South Wales in urban, rural and remote areas with a total of 333 participants, most of whom were Indigenous peoples.

A qualitative study was conducted in metropolitan Perth and the Kimberley regions of Western Australia during the years 2000-2002 [15,32]. The study took place with a high level of ongoing collaborative processes with key Aboriginal subjects within the various communities, which resulted in an 'Aboriginal community-derived methodology'. No theoretical framework is detailed beyond a statement that this was a qualitative study, but it appears that the study was conducted along the lines of participatory action research. This study included 70 Aboriginal participants with participant selection details and demographic information provided. Data collection consisted of interviews conducted with all informants, followed by eight focus groups. The data analysis process consisted of thematically analysing the text; with no philosophical framework underpinning the process detailed. Focus groups were held after initial data analysis to allow original informants to culturally validate the data and interpretations. The study focused on Aboriginal people's beliefs and attitudes towards mental health, Western psychology and practitioners, and ways to improve delivery of mental health care. Two articles were included from this study. Vicary and Bishop's article focused specifically on Aboriginal traditional frameworks of healing and Western psychotherapeutic treatments [32] while Vicary and Westerman's article considered Aboriginal mental health beliefs [15].

Emden et al. used an action research framework to investigate medication use by Indigenous people with mental health problems in 2003 [11]. That study was undertaken in urban, rural and remote areas of South Australia using semi-structured in-depth interviews as well as focus group interviews. More than 130 participants who were patients, carers or mental health workers (the majority of whom were Aboriginal) constituted a convenience sample selected to maximize representation of key stakeholders. No information was provided regarding age or gender of the participants, or how many participants were in each category. Field notes and steering committee discussions were included as part of data collection. Data analysis incorporated two stages: regional analysis and a meta-analysis. The analysis was iterative, in keeping with qualitative methodologies, and analysis was cross-validated by different researchers. Meta-analysis compared the findings across the different study settings. Although the focus of the research was medication usage, in-depth interviews provided some data regarding social and emotional well-being, therefore that study was included in the meta-synthesis.

A qualitative study by O'Brien was conducted in an Aboriginal community in New South Wales but the year of the study was not stated [33]. Potential participants were purposively selected to be interviewed, with 27 agreeing to participate. The study design was interpretive and predominantly ethnographic, utilizing participant observation, field notes and in-depth interviews. The verbatim transcripts were analysed using principles of grounded theory. The aim of that study was to consider the problems faced by Indigenous youth with a focus on mental health in order to develop a greater cultural appreciation of these issues [33]. However, the number of adolescent participants was low. Interviews were conducted with 27 Indigenous participants, 18 female and nine male. Of the female participants, five were between 15 and 20 years of age, while there were seven male subjects between 15 and 35 years of age. It is not stated why the researcher did not provide the same age breakdown for female and male participants, therefore it is unknown how many male participants were adolescents. The maximum age of the participants was between 50 and 60 years. That study included numerous verbatim quotes from the participants and clearly identified those from the adolescent participants.

McLennan and Khavarpour conducted an exploratory study in 2003 with six participants in an Indigenous community in New South Wales [34]. Participants were purposively approached to be involved by Indigenous community members. The age range and gender of the participants was not detailed. That study was the weakest in terms of reported methodological detail. The article did not include any information on the theoretical underpinnings of the research methodology, nor of the data analysis process. However, the methods used to collect the data were qualitative; semistructured interviews were used to explore the connections between well-being and spirituality. It was a small study with six participants and was limited to the connection between spirituality and well-being. It was included in the meta-synthesis because it used qualitative methods to gain an understanding of Indigenous people's perspectives of well-being, a key construct in a holistic approach to overall health, including mental health.

Aspects of each of these four studies were concerned with developing an understanding of Indigenous people's perceptions of mental health and/or well-being, but no study explicitly set out to examine how Indigenous people understand or conceptualize mental disorders. Throughout the studies the phrase 'mental illness' appears to be used as a generic term or substitute for 'mental health problem' or 'mental disorder' with no meaning, definition or scope detailed, with the exception of Vicary and Westerman, who refer to depression and anxiety-related disorders when using the term 'mental illness' [15]. The Emden et al. study included the perceptions of mental health services patients [11] while the other studies provided little detail regarding the participants' roles. With the exception of the O'Brien study [33], a perception of mental health across multiple age groups was not identified as an aim of the studies. 


\begin{tabular}{|c|c|c|c|c|c|}
\hline & Vicary and Bishop [32] & $\begin{array}{c}\text { Vicary and } \\
\text { Westerman [15] }\end{array}$ & Emden et al. [11] & $\begin{array}{c}\text { McLennan } \\
\text { and Khavarpour [34] }\end{array}$ & O'Brien [33] \\
\hline Culture Spirituality & $\begin{array}{l}\text { Importance of country } \\
\text { Influence of spirituality } \\
\text { Culture: 'powerful } \\
\text { determinant' of } \\
\text { perceptions of mental } \\
\text { health } \\
\text { Cultural identity }\end{array}$ & $\begin{array}{l}\text { Mechanism of } \\
\text { interpretation: } \\
\text { cultural reasons sought } \\
\text { for ill health } \\
\text { Treatment dependent on } \\
\text { cultural interpretation }\end{array}$ & $\begin{array}{l}\text { Mismatch between } \\
\text { traditional and Western } \\
\text { understandings of health } \\
\text { and illness }\end{array}$ & $\begin{array}{l}\text { Importance of identity Sacred } \\
\text { sites }\end{array}$ & $\begin{array}{l}\text { Loss of cultural identity } \\
\text { Lack of respect } \\
\text { Importance of Aboriginal } \\
\text { identity } \\
\text { Individual (mainstream) } \\
\text { versus the community }\end{array}$ \\
\hline Kinship & $\begin{array}{l}\text { Diminished } \\
\text { traditional roles }\end{array}$ & & $\begin{array}{l}\text { Family and community } \\
\text { tensions }\end{array}$ & $\begin{array}{l}\text { Basis of identity Sense of } \\
\text { belonging }\end{array}$ & $\begin{array}{l}\text { Traditional kinship roles } \\
\text { Role of elders } \\
\text { Importance of family } \\
\text { Lack of role models within } \\
\text { community Lack of support } \\
\text { in community }\end{array}$ \\
\hline $\begin{array}{l}\text { Social Historical } \\
\text { Economic }\end{array}$ & $\begin{array}{l}\text { Impact on wellness } \\
\text { - employment, } \\
\text { substance abuse, family } \\
\text { violence, dispossession, } \\
\text { Stolen Generation, } \\
\text { financial problems, } \\
\text { housing }\end{array}$ & & $\begin{array}{l}\text { Grief and anger over past } \\
\text { injustices } \\
\text { Racism } \\
\text { Low self-esteem } \\
\text { Stolen generation } \\
\text { Grief due to loss of family } \\
\text { members } \\
\text { Social and emotional stress } \\
\text { Overcrowding } \\
\text { Effects of alcohol misuse }\end{array}$ & & $\begin{array}{l}\text { Intergenerational impact of } \\
\text { colonial domination } \\
\text { Social oppression and racism } \\
\text { Impact of alcohol and drugs } \\
\text { Domestic violence and other } \\
\text { abuse } \\
\text { Grief }\end{array}$ \\
\hline Fear Education & $\begin{array}{l}\text { Stigma therefore need for } \\
\text { education } \\
\text { Lack of awareness of } \\
\text { mental health issues } \\
\text { Lack of culturally } \\
\text { appropriate mental } \\
\text { health promotion } \\
\text { Mental illness as } \\
\text { 'culturally alien' } \\
\text { Fear of treatment } \\
\text { outcomes }\end{array}$ & $\begin{array}{l}\text { Fear of Western mental } \\
\text { health system: } \\
\text { reluctance to seek help } \\
\text { Stigma and shame } \\
\text { attached to mental } \\
\text { illness } \\
\text { Need for education to } \\
\text { improve skills and } \\
\text { knowledge } \\
\text { 'Depression' seen as a } \\
\text { character of individual } \\
\text { therefore cannot be } \\
\text { treated by medication }\end{array}$ & $\begin{array}{l}\text { Relevant and accessible } \\
\text { education required } \\
\text { Lack of knowledge regarding } \\
\text { medication }\end{array}$ & & $\begin{array}{l}\text { Understanding of mental } \\
\text { health 'medically simplistic } \\
\text { and nailve' }\end{array}$ \\
\hline
\end{tabular}




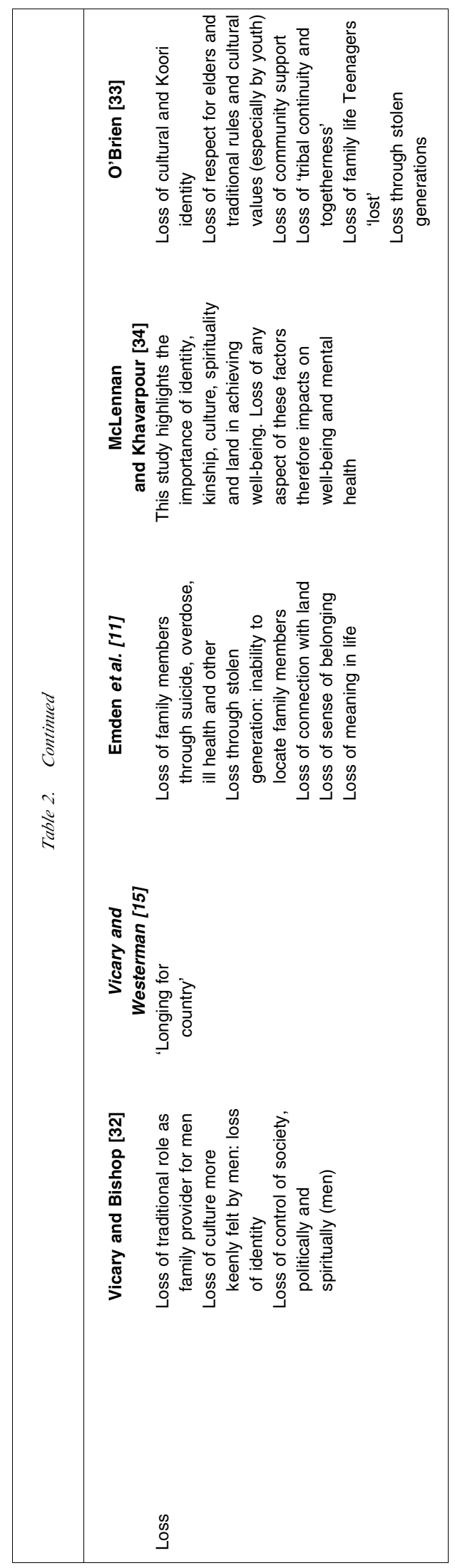

\section{Findings}

We used to call them Womba, yeah; they're funny in the head. The term mental health to me is that state of my mind and you know you're not sick in your mind. (p. 13) [33]

Five themes regarding Indigenous understandings of mental health and mental disorders emerged from the process of reciprocal translation and synthesis: (i) culture and spirituality; (ii) family and community kinships; (iii) historical, social and economic events; (iv) fear and education and (v) loss in its many manifestations.

An overarching construct that became apparent from the synthesis of the studies was the dynamic interconnectedness of culture, spirituality, identity, family and community, land/country, socioeconomic status, and sociohistoric events, with each defining, influencing, being part of and impacting on the other. Each of the themes arising from the reciprocal translation can be considered within the meta-theme of dynamic interconnectedness. This dynamic interconnectedness means that no single aspect of an Indigenous person's life circumstance can be considered successfully in isolation from other areas of life; no theme appears to exist without the other themes influencing and impacting on mental health.

\section{Culture and spirituality}

Three of the studies (four articles) acknowledged the importance of and the link between spirituality and well-being [15,32-34]. Spirituality plays an integral and crucial role in Aboriginal culture $[33,34]$ and well-being [34]. Strong links with individual and community well-being, storytelling, ceremonies, ancestors, sacred sites, and tribal areas all impact on a sense of positive identity and are connected to individual and community well-being $[33,34]$. Identity is also identified as a component of spirituality and culture [32-34].

Cultural and/or spiritual causes for mental illness were often considered when a person became unwell $[32,33]$. The onset of mental illness could be perceived as payback for previous transgressions, being 'sung to', married the 'wrong way' and other cultural and spiritual reasons [32,33]. One participant provided a narrative that involved someone being 'sung to' when asked to describe mental health [33]. A weakness in wellness was perceived to predispose a person to illness and increase vulnerability, allowing malevolent 
spirits to influence a person [15]. Aboriginal people accessed traditional mental health services in response to the causative role of spiritual or cultural factors [32]. Only when all traditional avenues had been tried would a person turn to Western models of treatments [15,32]. A difference in treatment modalities was highlighted with Western treatments perceived to be more focused on medication, counselling and hospitalization, whereas traditional treatments included methods to build resilience against spirits to increase wellness [15].

\section{Family and community kinship}

Family is considered to be pivotal to emotional, physical and cultural health [33]. Family and community relationships are the basis of culture and are important to cohesion and to healing within a community $[11,33,34]$. Supports that previously existed within a more traditional community are diminished and the tribal rules traditionally passed down by elders are often not viewed as important to the youth of today [33]. A result of this diminishing role of community is that people, and youth in particular, may be left to resolve their own emotional problems without the support of the community [33].

Concerns regarding alcohol misuse and their impact on family and community life and mental health were raised. In one study alcohol and substance abuse was seen as a leading cause of community disintegration. These participants considered that the effects of alcohol misuse acted as a catalyst for a variety of community concerns: domestic violence, unemployment, depression, sexual assault and the early deaths of relatives and friends [33]. Another study argued that drinking was a symptom of a larger issue concerning the lack of meaningful life circumstances [11].

\section{Historical, social and economic factors}

A complex mixture of events and consequent impacts has occurred since colonization. Three studies (four articles) acknowledged connections between historical events and current socioeconomic situations $[11,15,32,33]$. O'Brien succinctly argued that the 'price of colonial domination across generations for so many years has been pervasive and relentless' [33]. One participant clearly articulated the following:

It's so complex ... just the intergenerational trauma. The grief and loss of disconnection with land and families and ... not having a sense of belonging anywhere. It's all that ... lack of self-esteem, lack of identity ... [11].

Participants in a number of studies commented on multiple factors that impact on wellness including employment, overcrowding, family violence, the stolen generation, poor physical health, substance abuse and financial difficulties [11,32,33].

In concert with the effects of colonization are the impacts of living in a socially marginalized and oppressed position $[11,32,33]$. Social inequalities and racism (overt and covert) lead to low self-esteem and feelings of worthlessness [11]. Youth do not always have the opportunity to consider their own mental health needs and status while their parents and other relatives are caught up with the sociohistorical conditions of inequality [33].

\section{Fear and education}

Many Aboriginal people expressed fear of Western mental health services: both treatment and practitioners $[15,32]$. Shame and the stigma attached to mental illness and the labelling impact of diagnosis were cited as reasons to avoid Western services [15,32]. Previous experiences of family or other community members who have had contact with Western mental health services impacted on their understandings of Western models of treatment; in particular, being hospitalized away from country and the impact of medication on the person's ability to fulfil their familial and social roles in the community [15]. This fear often meant that families would try to cope by themselves with a mentally ill person, delaying Western treatment until crisis point [15].

Concomitant with the fear of Western treatment modalities were statements made by many participants regarding the lack of culturally appropriate mental health information [32]. Participants argued the need for more education to provide skills and knowledge to seek assistance and overcome stigma $[11,15]$. The importance of education could be seen strongly with depression as some participants argued that Aboriginal people considered depression to be 'characterlogical': 'that's just the way he is' [15]. Therefore depression may often be ignored until a person's behaviour becomes visible, resulting in delayed treatment, by which time the condition may be severe. The lack of recognition and subsequent treatment may be a contributing factor to the higher frequency of suicide and hospitalizations [15]. 


\section{Loss}

Loss was not specifically identified in the studies, with the exception of O'Brien who identified 'loss of cultural identity' as a theme [3]. However, evidence of pervasive loss across all areas that surrounded the conceptualization of mental health was consistent across all studies. Although not specifically identified by individual studies, loss was manifested in many ways across the studies. This loss appeared to underscore many aspects of spiritual, cultural, social, economic and emotional domains and played a role in perpetuating the intergenerational impact of historical events.

The loss of identity, both spiritual and cultural, impacts on self-esteem and emotional well-being and on one's ability to cope with stressful situations [33]. Loss of family was seen through the impact of the stolen generations, suicide, early death and incarceration. Additionally there was a loss of community through diminishing community traditions [11,33]. The impact of family violence, alcohol and other substance misuse and tensions in families all point to a loss of traditional family and community values $[32,33]$. Indigenous people have experienced loss of culture, spirituality and land/country through the early experiences of colonization and ongoing social practices and government policies [11,32,33]. Alongside the aforementioned losses is the associated loss of roles, both for the community in general and for individuals, in particular elders and male Indigenous people [32,33].

A loss of respect for and importance of the ways things were once done is also apparent [33]. Loss of control, power and hope to bring about balance in their life impacts on social and emotional well-being [11]. This theme of loss was pervasive across spiritual, cultural, social, economic and emotional domains.

\section{Discussion}

An extensive search of medical and sociological databases found only four published empirical studies that explored Indigenous people's understandings of mental health. These four studies included Indigenous people in multiple settings: urban, rural and remote as well as across three Australian states. By using meta-synthesis as the methodological framework the reach of the individual studies is extended beyond their initial setting. The use of meta-synthesis is new and has an important role to play in informing future qualitative literature reviews. Typically research using qualitative methodologies has a small number of participants because the aim is for an in-depth understanding of the topic or question under consideration, but the meta-synthesis allowed the perceptions of 333 participants to be considered. Sandelowski et al. caution against the use of large numbers of studies and participants because it may hinder the deep analysis and interpretive validity inherent in qualitative inquiry [23].

By synthesizing these qualitative studies a greater depth of knowledge about particular Indigenous communities has been achieved than available in individual studies. An overarching theme of dynamic interconnectedness was consistent throughout these studies and expressed in many ways by individual authors. Working with the original findings for the meta-synthesis demonstrated the difficulties inherent in attempting to define Indigenous people's understandings of mental health and mental disorders. Each aspect or theme developed could be seen to impact on, or was impacted by, others, causing a continuous cycle that appeared to defy simplification. Authors described this by using phrases such as 'a multi-directional relationship' [34] or compiled lists of the various factors they identified to be associated with mental health and well-being $[11,15,32,33]$. Concomitantly there are known factors that impact on mental health, such as trauma and the lack of selfdetermination, that while of great significance, were not highlighted by the findings of the studies. The lack of emphasis by Indigenous participants in these areas may need to be explored further.

The construct of 'holistic health' was used in articulating Indigenous people's understandings of mental health $[11,15,32-34]$. However, 'holistic' was loosely defined, with differing factors in each study considered to be aspects of a holistic approach to health and well-being. Studies considered holistic health to contain elements that are cultural and spiritual [32], incorporate individual, family and community biopsychosocial issues [11] and cover a range of personal and environmental factors [15]. Social and emotional well-being was another construct often used because it includes all aspects of life: social, emotional, economic and physical factors [11]. O'Brien argued that mental health is tied to culture, kinship and community, as well as issues surrounding identity and spirituality, [33] while McLennan and Khavarpour argued the need to understand the relationship between mind, body and spirit [34].

Research such as the ones identified here, as well as other reports, expert commentaries and opinion pieces, have documented multiple causes of poor 
mental health related to the impact of colonial history and socioeconomic disadvantage. The studies reviewed for the meta-synthesis are driven from the constructs of emotional and social well-being and holistic health. While studies such as these add significantly to the knowledge base about well-being and overall health, they are limited in providing clear understandings of how Indigenous people define, describe, understand and cope with mental disorders and mental health problems. Overall these studies do not provide in-depth narratives of the lived experience of mental disorders from the perspectives of those with mental disorders or mental health problems, their families/carers or those within the community.

There remains a need for Indigenous voices to be heard in order to explore and gain greater knowledge of their conceptualizations of mental disorders and to consider these in relation to Western biomedical conceptualizations. Cross-cultural psychiatry emphasizes the importance of acknowledging the impact of differing cultural beliefs on conceptualizations of mental health. Of import is that Indigenous people do not constitute one homogenous cultural group, and furthermore differences in cultural beliefs may vary according to place of living: urban, rural or remote. For example, those living in urban areas may have been influenced by Western conceptualizations surrounding them, resulting in a hybridization of cultural beliefs and understandings about mental disorders. The impact of globalization such as the media may also play a role in shaping such understandings [19].

A key outcome of this meta-synthesis is the identification of the following gaps in knowledge that have not been adequately answered in empirical studies to date: what narratives do Indigenous people tell to understand and describe mental disorders from a construct of wellness; what language is used by Indigenous people to construct mental disorders and mental health problems; and what correlation is there to Western biomedical labels and diagnoses; what cultural beliefs/practices may be beneficial or harmful to mental health well-being; what is the impact of dynamic change on Indigenous youth and their mental health. There is a need to know how Indigenous people experience coping and caring for individuals with mental health needs in their family and wider community, and how they determine the need to seek out traditional or Western models of treatment. These questions require further empirical research to enable a more sophisticated understanding of Indigenous people's constructions of mental health and mental disorders and to apply this knowledge to effective service delivery both for those experiencing mental disorders, their carers and their community.

There is a disjunction between traditional Indigenous understandings and knowledge of wellness, and Western medicoscientific constructs of mental health and mental disorders [11,35]. Without an in-depth understanding of Indigenous mental health issues, from Indigenous perspectives, many mental health services may continue to be delivered from a Western biomedical framework of illness, serving to maintain the status quo. What is required as a consequence of the social and cultural changes experienced by Indigenous people is an expansion of biopsychosocial models to encompass sociocultural and spiritual aspects [36]. The role of spirituality in Indigenous well-being is a critical determinant in the development of promotion and prevention projects and this importance was evidenced in the meta-synthesis $[15,32-34,37]$. There is a need to acknowledge the healing frameworks that exist within Indigenous communities, and to acknowledge cultural frameworks of learning, thereby utilizing the power of culture and community $[32,38]$.

Working concurrently with the necessity of increasing Western understandings of Indigenous perceptions of mental health problems is the need to augment Indigenous understandings about the nature of mental disorders, as well as services and their roles that are available within mainstream health services $[14,39,40]$. The Social and Emotional Well-being Framework for Indigenous Australians recognizes the necessity of successful partnerships between Indigenous people and mainstream health-care services and the development of strategies that are local and specific [41]. There is a lack of Indigenous labels for mental disorders and a difficulty in understanding the Western biomedical model with its associated diagnoses and labelling [39]. Increased knowledge may help overcome the stigma attached to mental disorders and mental health problems and hence increase help-seeking behaviours and earlier access to mental health care [42].

The importance of understanding Indigenous descriptions and perceptions of mental health issues is crucial to begin to make connections between Indigenous communities and Western mental health professionals; to diminish the boundaries between Indigenous narratives and constructs of wellness and Western biomedical diagnostic labels and treatment pathways for mental disorders and mental health problems. Approaches that draw on Indigenous 
understandings to inform Western knowledge afford the opportunity to work collaboratively with/in these perspectives to develop culturally appropriate and sensitive mental health and well-being programmes. Such approaches provide a unique opportunity to develop 'two-way understandings' between Indigenous people and Western models of care that will go a long way to realizing successful mental health outcomes by and for Indigenous people.

\section{Acknowledgements}

This meta-synthesis was funded through the Australian Integrated Mental Health Initiative (AIMhi), which is supported by a NHMRC Partnership Grant in Mental Health (219327), and an Australian Health Ministers' Advisory Council Priority Driven Research grant in population health: Empowerment of patients, carers and communities to support people with mental illness in remote Indigenous Cape York communities.

\section{References}

1. Collinson SL, Copolov DL. Challenges and opportunities for mental health research in Australia. J Ment Health 2004; 13:29-36

2. Jorm AF, Griffiths KM, Christensen H, Medway J. Research priorities in mental health, part 1: an evaluation of the current research effort against the criteria of disease burden and health system costs. Aust N Z J Psychiatry 2002; 36:322-326.

3. Griffiths KM, Jorm AF, Christensen H, Medway J, Dear KB. Research priorities in mental health, Part 2: an evaluation of the current research effort against stakeholders' priorities. Aust N Z J Psychiatry 2002; 36:327-339.

4. Commonwealth Department of Health and Aged Care. Promotion, prevention and early intervention for mental health: a monograph. Canberra: Mental Health and Special programs Branch, 2000.

5. Laugharne J, Glennen M, Austin J. The 'Maga Barndi' mental health service for Aboriginal people in Western Australia. Australas Psychiatry 2002; 10:13-17.

6. Hunter E. "Best intentions" lives on: untoward health outcomes of some contemporary initiatives in Indigenous affairs. Aust N Z J Psychiatry 2002; 36:575-584.

7. Burdekin B. Report of the National Inquiry into the human rights of people with mental illness. Human rights and mental Illness. Canberra: Australian Government Publishing Service, 1994.

8. Australian Institute of Health and Welfare. Mental health . Canberra: Commonwealth of Australia, 2004.

9. DeLeo D, Travis H. Suicide in Queensland 1999-2004: mortality rates and related data. Brisbane: Griffith University, 2004.

10. Roxbee L, Wallace C. Emotional and social wellbeing: national policy context. Australas Psychiatry 2003; 11:45-50.

11. Emden C, Kowanko I, de Crespigny C, Murray G. Better medication management for Indigenous Australians: findings from the field. Aust J Prim Health 2005; 11:80-90.
12. Swan P, Raphael B. Ways forward: national Aboriginal and Torres Strait Islander mental health policy, national consultancy report. Canberra: Commonwealth of Australia, 1995.

13. Adams C. Ethics, power and politics in Aboriginal health research. Asia Pac J Anthropol 2002; 3:44-64.

14. Queensland Health. Queensland Mental Health Policy Statement: Aboriginal and Torres Strait Islander people. Brisbane: Queensland Health, 1996.

15. Vicary DA, Westerman T. 'That's just the way he is': some implications of Aboriginal mental health beliefs. Aust $J$ Adv Ment Health 2004; 3:1-9.

16. Moldavsky D. Transcultural psychiatry for clinical practice. Psychiatric Times 2004; 21:39-41.

17. Kirmayer L, Minas HI. The future of cultural psychiatry: an international perspective. Can J Psychiatry 2000; 45: $438-$ 446.

18. Yeh CJ, Hunter CD, Madan-Bahel A, Chiang L, Arora AK. Indigenous and interdependent perspectives of healing: implications for counseling and research. J Counsel Dev 2004; 82:410-419.

19. Kirmayer L. Beyond the 'new cross-cultural psychiatry': cultural biology, discursive psychology and the ironies of globalization. Transcult Psychiatry 2006; 43:126-144.

20. Hsioa F, Klimidis S, Minas HI, Eng ST. Folk concepts of mental disorders among Chinese-Australian patients and their caregivers. J Adv Nurs 2006; 55:58-67.

21. Brettle AJ, Long AF. Comparison of bibliographic databases for information on the rehabilitation of people with severe mental illness. Bull Med Libr Assoc 2001; 89:353-362.

22. Campbell R, Pound P, Pope $\mathrm{C}$ et al . Evaluating metaethnography: a synthesis of qualitative research on lay experiences of diabetes and diabetes care. Soc Sci Med 2003; 56:671-684.

23. Sandelowski M, Docherty S, Emden C. Qualitative metasynthesis: issues and techniques. Res Nurs Health 1997; 20:365-371.

24. Smith LK, Pope C, Botha JL. Patients' help-seeking experiences and delay in cancer presentation: a qualitative synthesis. Lancet 2005; 366:825-831.

25. Downe S, Simpson L, Trafford K. Expert intrapartum maternity care: a meta-synthesis. $J$ Adv Nurs 2007; 57:127140.

26. Noblit GW, Hare RD. Meta-ethnography: synthesizing qualitative studies. London: Sage Publications, 1988.

27. Britten N, Campbell R, Pope C, Donovan J, Morgan M. Using meta ethnography to synthesise qualitative research: a worked example. J Health Serv Res Policy 2002; 7:209-215.

28. Tse S, Lloyd C, Petchkovsky L, Manaia W. Exploration of Australian and New Zealand indigenous people's spirituality and mental health. Aust Occup Ther J 2005; 52:181-187.

29. Walsh D, Downe S. Meta-synthesis method for qualitative research: a literature review. Methodol Issues Nurs Res 2005; 50:204-211.

30. Downe S, Simpson L, Trafford K. Expert intrapartum maternity care: a meta-synthesis. $J$ Adv Nurs 2006; 57:127140.

31. Pound P, Britten N, Morgan M et al . Resisting medicines: a synthesis of qualitative studies of medicine taking. Soc Sci Med 2005; 61:133-155.

32. Vicary DA, Bishop BJ. Western psychotherapeutic practice: engaging Aboriginal people in culturally appropriate and respectful ways. Aust Psychologist 2005; 40:8-19.

33. O'Brien A. Factors shaping Indigenous mental health: an ethnographic account of growing up Koori from a Gubba perspective. Aust J Holistic Nurs 2005; 12:11-20.

34. McLennan V, Khavarpour F. Culturally appropriate health promotion: its meaning and application in Aboriginal communities. Health Prom J Aust 2004; 15:237-239. 
35. Maher P. A review of 'traditional' aboriginal health beliefs. Aust J Rural Health 1999; 7:229-236.

36. Haswell-Elkins M, Hunter E, Nagel T et al. Reflections on integrating mental health into primary health care services in remote Indigenous communities in Far North Queensland and the Northern Territory. Aust J Prim Health 2005; 112:62-69.

37. Ypinazar V, Margolis S. Delivering culturally sensitive care. Qualitat Health Res 2006; 8:773-787.

38. Davis B, McGrath N, Knight $\mathrm{S}$ et al. Aminina nud mulumuluna ("You gotta look after yourself"): evaluation of the use of traditional art in health promotion for Aboriginal people in the Kimberley region of Western Australia. Aust Psychologist 2004; 39:107-113.
39. Brown R. Australian Indigenous mental health. Aust $N Z J$ Ment Health Nurs 2001; 10:33-41.

40. Herrman H. The need for mental health promotion. Aust $N Z$ J Psychiatry 2001; 35:709-715.

41. Social Health Reference Group. Social and emotional well being framework: a national strategic framework for Aboriginal and Torres Strait Islander mental health and social and emotional well being 2004-2009. Canberra: Department of Health and Ageing, Australian Government, 2004.

42. Williams S. The Indigenous Australian health worker: can research enhance their development as health and community development professionals? Aboriginal Islander Health Worker $J$ 2001; 25:9-15. 